\title{
Relationship Between Electromyographic Frequency of the Erector Spinae and Location, Direction, and Number of Spinal Curvatures in Children with Scoliotic Changes
}

Jacek Wilczyński (iD

Przemysław Karolak

Laboratory of Posturology, Collegium Medicum, Jan Kochanowski University in Kielce, Kielce, Poland
Correspondence: Jacek Wilczyński Tel +48 603-703-926

Email jwilczyński@onet.pl
Introduction: The aim of the study was to assess the relationship between erector spinae electromyographic frequency (SEMG) and the location, direction and number of spinal curvatures in children with scoliotic changes.

Methods: Analysis comprised 103 (42,21\%) children with scoliosis and 141 (57.79\%) with scoliotic posture. Body posture and the spine were examined using the Diers formetric III 4D optoelectronic method. Electromyographic analysis was performed using a 14-channel Noraxon TeleMyo DTS apparatus.

Results: In girls, the highest mean SEMG frequency of the erector spinae, calculated from 16 measurements, occurred in the case of scoliotic posture (Mean $=73.69 \mathrm{~Hz})$, while in boys, the greatest values were noted for scoliosis (Mean $=79.75 \mathrm{~Hz}$ ). There was a significant correlation between erector spinae SEMG frequency and curvature location, both in the scoliosis group $(p=0.003)$ and in the group with scoliotic posture $(p=0.04)$. There was also a significant correlation between SEMG frequency of the erector spinae and direction of the curvature, both in the scoliosis $(p=0.01)$ and scoliotic posture groups $(p=0.04)$, as well as between the erector spinae SEMG frequency and the number of spinal curvatures (scoliosis group: $p=0.03$; scoliotic posture group: $p=0.03$ ).

Conclusion: The study is of applicative value and fills the gap in research on erector spinae SEMG frequency of in low-grade scoliosis among small children. Our research can also be used in research on the etiology and progression scoliosis. Visible disturbances in the erector spinae SEMG frequency (activity and tension) contribute to the development of curvature and testify to the fact that these changes are the primary cause of idiopathic scoliosis. Scoliosis is merely a symptom, an external expression of CNS dysfunction that is not fully recognised. It is also visible on the SEMG record of postural muscles. Our objective is to contribute to creating a future model record for SEMG of the postural muscles, characteristic for children with scoliosis. Then, based on electromyographic examination, it will be possible to identify initial symptoms of scoliosis and start preventive rehabilitation before irreversible bone changes occur. Keywords: frequency electromyography of the erector spinae, surface topography, scoliosis, scoliotic posture

\section{Introduction}

Idiopathic scoliosis regards developmental deformity of the spine and body posture. The nature of this deformation is 3-dimensional. In the frontal plane, lateral curvature of the spine occurs, while in the sagittal plane, there is a disturbance of 
physiological thoracic kyphosis or lumbar lordosis. Furthermore, in the transverse plane, rotation and vertebral torsion take place. $^{1,2}$ Deformation develops simultaneously in all 3 planes (spinal torsion). The disease occurs during the growth of the spine. ${ }^{3,4}$ In the initial period, spontaneous evolution is sometimes visible, which can be an increase in the distortion, its resolution or stabilisation. ${ }^{5,6}$ In epidemiological studies, it has been shown that in $20 \%$ of scoliosis cases, there is more or less regression of changes, while scoliosis remains stable in $70 \%$, but in $10 \%$ of scoliosis, progression occurs. ${ }^{7}$ If the idiopathic curvature of the spine with a Cobb angle of $10^{\circ}$ or above shows progression of $5^{\circ}$ or more per year, this may be considered progressive scoliosis. ${ }^{5}$ The greatest tendency towards progression occurs in girls with rightor left-sided thoracic and left-sided lumbar curvatures. ${ }^{8}$ Curvatures accompanied by flat backs, scoliosis with reduced lateral mobility, with short curvatures, high rotation and with structural changes in the vertebral bodies, have poor prognosis. The highest risk of progression occurs between the age of 10 and $13 .{ }^{8}$ In adolescents, curvature progression is noted in $13 \%$ of cases, and in boys, only in $0.14 \% .^{7}$ Progression depends on the type of curvature, its size, the age of the child at the time of diagnosis and the value obtained on the Risser test. ${ }^{8}$ Growth distortions of the skeletal system and soft tissues are joined by primary displacements. At a developmental age, idiopathic scoliosis occurs in $2-3 \%$ of the adolescent population. Slight scoliosis is frequently diagnosed both in girls and boys. ${ }^{6}$ As the angular value increases, the proportion becomes unfavourable for girls. They are also at a greater risk of curvature progression. ${ }^{7,8}$ Scoliosis requiring treatment affects $1 \%$ of the adolescent population. In Poland, this corresponds to about 5000 patients each year. ${ }^{9}$ In our research, performed using the surface topography method via the Diers formetric III 4D, it was demonstrated that scoliosis occurred in $3.65 \%$, while scoliotic posture was present in $53.49 \%$ of school children. ${ }^{10}$ The basic problem is not the pain or respiratory and circulatory system disorders typical for adults, but the risk of deformity progression in children with this disease. It becomes greater the sooner scoliosis occurs. It is larger in girls than in boys and is also greater in primary double than in single-curvature scoliosis. Additionally, the greater the loss of physiological thoracic kyphosis and the angle of curvature at the time of detection, the greater the scoliosis. The location, direction and number of spinal curvatures are typical changes in the development of scoliosis. ${ }^{11}$
Many divisions have been proposed and new ones are still being published. Idiopathic scoliosis was chronologically divided by James into infantile, juvenile and adolescent. ${ }^{12}$ Infantile scoliosis occurs in the first 3 years of life. Juvenile scoliosis manifests itself from the age of 3 to the onset of puberty. In contrast, adolescent scoliosis occurs during puberty. The earlier scoliosis occurs, the longer it develops and the more it causes distortion. Infantile scoliosis is an exception, among which regressive and progressive scoliosis can be distinguished.

Schulthess noted 5 basic types of idiopathic curvatures: cervical-thoracic, thoracic (most often right-sided), thoracolumbar, lumbar (most often left-sided), double thoracic and lumbar (most often right-sided while lumbar is left-sided). ${ }^{13}$ Lenke distinguished 6 types of scoliosis based on the number and location of spinal curves: type 1 - single-curvature thoracic scoliosis (MT-main thoracic); type 2 - double thoracic scoliosis (DT- double thoracic); type 3 - thoracic and lumbar double scoliosis with predominance of thoracic (DM - double major); type 4 - triple major scoliosis (TM - triple major); type 5 - single thoracolumbar scoliosis or single lumbar scoliosis (TL/L - thoracolumbar/lumbar); type 6 - double scoliosis with predominance of lumbar or thoracolumbar curvature (TL/L-structural MT - thoracolumbar/lumbarstructural main thoracic). ${ }^{14}$

The cause of this condition is unknown. The accumulation of great amounts of data, often contradictory, has not yet aided the determination of scoliosis etiology, and therefore, it is still called idiopathic scoliosis. Among scoliosis cases, $90 \%$ are of unknown etiology. No universally accepted theory of scoliosis etiopathogenesis exists. There is agreement that idiopathic scoliosis is multifactorial. In extensive literature regarding this field, abnormalities are described at the level of systems, organs, tissues, cells, particles and genes, without prejudging their primary or secondary nature., ${ }^{9,15}$ Although scoliosis is obviously a distortion of the body, it is also an effect of its compensatory ability, allowing the child to maintain the head and shoulder girdle in a position above the pelvis. The final shape of the trunk is the result of deformation processes and compensatory reactions, thanks to which the body, at the expense of a huge disorder in its own form, maintains the general orientation of the body. According to the current state of knowledge, it is justified to discuss etiological factors and not theory (genetic, metabolic, etc.) regarding the formation of scoliosis. It seems that currently, the multifactorial concept has the most supporters, including the genetically conditioned pathology of the 
central nervous system. This particularly regards the broadly understood postural system, which has a longlasting effect on the growing spine of a child with individually variable, multifactorial susceptibility to occurrence of distortion, most likely through the system of deep back muscles. Distortion progression is associated with growth and biomechanical factors. ${ }^{15}$

Dubousset et al $^{16}$ calls spinal torsion all spatial changes related to the mutual positioning of the vertebrae relative to each other, occurring during the development of idiopathic scoliosis. Moreover, 3-plane spinal torsion is a characteristic pathological process in idiopathic scoliosis. Exceeding a certain degree of distortion outside the stabilising range of the postural control system causes the development of a self-accelerating progression mechanism, which depends on mechanical factors and still functions even if the etiological factor disappears. ${ }^{16}$

In clinical studies, electromyographic frequency analysis is performed much less often than amplitude analysis. Research on the electromyographic frequency of the erector spinae is related to the issue of pathogenesis, etiology and scoliosis. The erector spinae muscle plays a special role in stabilising the spine. According to these authors, further stages of work on the etiology of scoliosis should be focused on issues related to the regulation of erector spinae muscle tone. ${ }^{17}$ The central nervous system is made up of many unknowns, the knowledge of which could explain the etiology of scoliosis or indicate what the next stages of research should be. When discussing the theory of muscular disorders, it should be emphasized that most of its supporters do not see etiologically primary disorders as the cause of spinal curvatures in the muscles. In their opinion, imbalances of muscle tension are secondary, a result of not yet studied changes occurring in the central nervous system. According to this theory, muscular imbalance leads to changes in the passive support apparatus of the spine, causing structural scoliosis. ${ }^{18}$

In the presented study, the authors only analysed the average frequency of the erector spinae surface electromyogram, which correlates to the activity of this muscle and its fatigue. EMG frequency tests are used to measure neuromuscular activity during functional movements and in therapy. This test consists in receiving and analysing myoelectric signals, resulting from the selective penetration of sodium and potassium ions in the cell membranes of muscle fibres. SEMG frequency determines the number of total signal periods per second. ${ }^{19}$ The unit of measurement for the frequency is Hertz $(\mathrm{Hz})$. SEMG frequency assessment takes both the characteristics of the potential of each motor unit individually, as well as the behaviour of the entire potential population into account.

This measurement provides valuable data not only on the extent of innervation of a given unit, but also on the density of muscle fibres within its territory and the number of motor units operating in a given muscle area. The frequency-related characteristics of SEMG are determined by changes occurring in the motor neuron membrane and the ratio of synaptic impulses as well as subsequent phenomena occurring after the previous stimulus. Impulses of motor units are conditioned by the impulse of motor neurons. The strength of muscle contraction can increase as a result of recruitment of new motor units as well as the increase in the frequency of discharges of a particular unit. With weak muscle contraction, the frequency of discharge of motor units is $7-10 \mathrm{~Hz} .{ }^{20}$ With a strong contraction, the frequency reaches $50 \mathrm{~Hz}$. On the other hand, with a fast, strong contraction, the frequency can even reach $100 \mathrm{~Hz}^{20}$ In the case of long-lasting contractions with a constant force, a decrease in frequency is observed, which can probably be explained by adaptation. As long as the subject is able to maintain a programmed muscle load, fatigue does not affect the frequency of discharge of motor units. However, along with fatigue of active muscle fibres, new units are gradually recruited. Changes in frequency are an important component of the mechanism of gradation of muscle contraction. Nonetheless, in different contraction conditions, with various strength ranges and in diverse muscles, the degree of participation of this component may vary. The potentials of motor units are not strictly rhythmic. ${ }^{21}$ When the number of active motor units increases, their potentials interfere.

Surface electromyography, even with the weakest muscle contraction, enables frequency recording, usually of an interference nature. The frequency of potentials in the interference recording is much higher than the frequency of motor unit discharges. This can only be explained by the asynchronous discharges of motor units. With simultaneous recording of the potentials of several units, it seems that each motor neuron sends impulses independently of the others. Asynchronous discharges of motor units ensure smooth muscle contraction at low-discharge frequencies. ${ }^{22}$ Interferential frequency recording with constant muscle contraction force is usually in the form of a sequence of irregular potential fluctuations. This can be divided into basic fluctuations, those crossing the zero line, and minor fluctuations superimposed on them. Interference recording 
is always symmetrical with regard to the zero line. For very low-frequency pulses, the recording may be asymmetrical, at high frequencies, this asymmetry disappears. The overall frequency depends on the strength of the contraction, which makes it possible to use exercise EMG to assess muscle function. The nature of the relationship between the intensity of the bioelectric frequency and the strength of muscle contraction depends on the conditions of the contraction. A linear relationship was found in isometric contraction, although some authors observed deviations from linearity (both ways), mainly regarding high loads. With muscle isotonic contraction, the frequency is more variable than with isometric contraction in the case of the same load. With a constant contraction rate, this is proportional to the load, and with a constant load - to the speed. In the case of contraction with muscle stretching, the activity is lower than in the case of contraction with shortening. ${ }^{23}$

The main reason for the higher muscle frequency along with greater contraction strength is the recruitment of motor units and increased discharges. Modelling of frequency recording, however, showed that assuming only these two factors is not enough to explain the linear relationship between frequency and contraction force. If only these factors are at work, the increase in frequency slows down and practically stops as soon as the saturation level is reached. ${ }^{24}$ When the muscle length changes, both the strength it develops and the size of the potential change, which affects their relationship. Thus, the relationship between frequency variability and the strength of muscle contraction is the resultant of several factors, which together, determine the even density of the record throughout the whole period of developed strength. In standard conditions, this relationship is close to being linear. ${ }^{24}$

Any muscle weakness leads to a decrease in its maximum electrical activity and in frequency. With the weakening of the muscle fibres themselves, the frequency at maximum contraction decreases. However, with high loads, it increases. This is because of fatigue due to the fact that a larger number of motor units must be recruited to maintain the same contraction force. The frequency in different muscles varies, depending on their structure, size and location. Inter-individual differences are also significant. The frequency is quite variable and the number of extreme deviations can range from 100 to $200 / \mathrm{s}^{25}$ The frequency of discharges and their duration are inversely proportional.
In studies, an increase in the bioelectrical activity of the erector spinae on the side of curvature convexity both at rest and at work can be noted. ${ }^{25}$ By means of pulsation, coming from the brain or cerebellum through animal or vegetative pathways, there is segmental tonic muscle contraction in the affected segments. The consequence of long-term isotonic contraction of the short muscles is rotation of the vertebrae and slowly increasing contracture of the rotator muscles and partly external and internal rib muscles. This entails contracture of the ligamentous connections of the spine, which is followed by functional shortening of the long muscles. ${ }^{25}$ It is not decisively explained how the EMG frequency image of the erector spinae muscles depends on the type of scoliosis and what changes occur in it during conservative treatment. If the direction of these changes could be determined, the EMG frequency analysis of the erector spinae could complement basic diagnostic tests and help to obtain more complete assessment of the treatment course.

The aim of the study was to assess the relationship between the SEMG frequency of the erector spinae and the location, direction and number of spinal curvatures examined by surface topography in children with scoliotic changes.

Main research problem: What relationships occur between the SEMG frequency of the erector spinae and the location, direction and number of spinal curvatures in children with scoliotic changes?

Main hypothesis: We assume that there is a significant relationship between the SEMG frequency of the erector spinae and the location, direction and number of spinal curvatures in children with scoliotic changes.

\section{Materials and Methods}

The study comprised 244 children, including 109 (44.67\%) girls and 135 (53.33\%) boys. There were 128 (52.46\%) 7-year-olds, among them $62(48.44 \%)$ girls and 66 (51.56\%) boys. There were $116(47.54 \%) 8$-year-olds, including 47 (40.52\%) girls and $69(59.48 \%)$ boys. The selection of participants was deliberate and consisted in choosing only those who met certain inclusion criteria for the study. The authors did not rely on chance and did not qualify all subjects for research, but we were guided by knowledge and the purpose of the undertaken research. The criteria for inclusion in the study were the presence of scoliosis, the occurrence of scoliotic posture, age 7-8 years, written consent of the parents or guardians for the examination. Exclusion criteria were CNS or locomotor 
disorders preventing proper psychomotor development, disorders that could be the cause of pathological posture: genetic syndromes, hormonal disorders, neuromuscular diseases, congenital motor system defects, age below 7 and above 8 years, lack of written consent for testing. Research was carried out in the Laboratory of Posturology at the Faculty of Medicine and Health Sciences of UJK in Kielce in 2017. All research procedures were carried out in accordance with the 1964 Declaration of Helsinki and with the consent of the University Bioethics Commission of Jan Kochanowski University in Kielce (Resolution No. 5/2015). The children and their parents were informed about the purpose of the study, its course and duration. All children and their parents provided written permission to participate in the study. The choice for testing children aged 7-8 years is associated with the fact that during the school period, there are two critical periods of posturogenesis, when the most postural defects and scoliosis occur. The first critical period, between the age of $6-8$, it is associated with a change in children's lifestyle. The essence of this change lies in the transition from a free, individually regime of movement regulated by the child - effort and rest in the imposed system of sitting for several hours, often in improper conditions. Therefore, during this period, care for ensuring proper living, working and leisure conditions for the child is particularly important. The second critical period of posturogenesis is associated with puberty (girls: 11-12 years, boys: 13-14 years). Examination of body posture and the spine began with clinical examination. Visual assessment of posture (symmetry test), the spine and the e-bend test (Adam's test) were performed, and the length of the lower limbs was also measured. Body posture and the spine were examined with surface topography using raster stereography. Three-dimensional analysis of the spine is a combination of optical imaging techniques and digital data processing. It is a fast and non-contact photogrammetric measurement and analysis of the patient's back and spine. The measurement results are very precise, and thanks to the quick transfer of the image to a computer, data analysis takes place immediately after the test. Because of the measurement, a precise diagnosis is possible, allowing selection of the best possible individual therapy. ${ }^{26}$ The room where the measurement was taken was darkened in a way that prevented direct sunlight from falling onto the patient's body. At a distance of about $3 \mathrm{~m}$ from the optical tripod, a dark background was mounted. During the measurement, the patient undressed to shorts and positioned his/her back to the camera at a distance of $2 \mathrm{~m}$. The patient assumed habitual posture. The projector emitted approximately $1-\mathrm{cm}$ wide horizontal stripes onto the patient's back. Body and spinal posture examination were performed using the DiCAM 2.4.9 programme, DIERS formetric 4D basic average. ${ }^{26}$ It consisted of taking a sequence of twelve frames of film, which by creating an average value, reduced postural variance and thus improved the clinical value of the study. The principle on which the test is based is of time-lapse photos in the shortest possible exposure time $(40 \mathrm{~ms}){ }^{26}$ In 2005 , this study was extended from the single-image to the multiimage method. Within 6 seconds, the test period covers 1 cycle of fluctuations (on average: 5, 6 seconds, approx. $300 \mathrm{~mm}$ forward/backward, $10 \mathrm{~mm}$ sideways), as well as one breathing cycle. ${ }^{26} \mathrm{Next}$, the computer programme analyses the data and determines the digital, photogrammetric image of the spine. Body posture examination was performed twice with a minute interval between the tests. The examiner (an experienced specialist in postural diagnostics and re-education), remembering the result of the clinical trial, decided which trial more accurately reflects the child's real habitual posture (posture habit) and only this test was further analysed. The body posture examination itself lasted about 15 minutes. The manufacturer of the Diers, formetric III 4D model number: 4D-65388 is DIERS International GmbH Dillenbergweg, Schlangenbad Germany. ${ }^{10,26}$ To make a proper diagnosis in the case of scoliotic changes, X-rays are very often used in addition to clinical examination. Also, follow-up examinations during the already implemented treatment require taking a series of X-rays at regular intervals, which is a problem from the point of view of radiation load, especially for children and adolescents. In a study conducted in Poland in 2012-2013, an alarmingly high percentage of exceedances was found for $\mathrm{AP} / \mathrm{PA}$ chest $\mathrm{X}$-rays over the entire age range, and especially for younger children. The reason is the lack of standard procedures and practical shortcomings in meeting the requirements of Polish regulations and the EURATOM Directive. ${ }^{27}$ According to Hartmann et al, ${ }^{28}$ the combination of a clinical trial and the surface topography method results in a reduction in the number of radiographs, which should be welcomed in the context of radiation load. Prujis et $\mathrm{al}^{29}$ estimated that the use of surface topography can eliminate up to $50 \%$ of radiography. ${ }^{29}$ Topographic measurements of the back surface partly meet these requirements and constitute an independent and promising alternative. $^{30}$ 
With the introduction of the video raster stereography (VRS) software platform by Drerup and Hierholzer, the possibility of sharing the principle of video raster stereography in screening was introduced for the first time. ${ }^{31,32}$ Reconstruction of the spatial course of the spine was possible on the basis of the Turner-Smith model. ${ }^{33}$ Its use in scoliosis cases shows results consistent with corresponding X-rays. The reliability of this measurement was confirmed by comparing 478 pairs of measurements by surface topography and X-ray images in 113 patients. ${ }^{31}$ This comparison gave a mean error (one standard deviation) of $3^{\circ}$ for vertebral rotation. This is a satisfactory result, especially since the radiological vertebral rotation error is also $3^{\circ} .{ }^{31}$ Comparing lateral deviation, an average error of $4 \mathrm{~mm}$ was obtained, so that the spine is satisfactorily compatible with the radiological course. ${ }^{31}$ A good result was also obtained when comparing pelvic skew and kyphosis and lordosis angles. For this reason, these surface measurements have a permanent place in the diagnosis and observation of scoliosis. ${ }^{34}$ However, the reconstructed centre-line does not allow assessing the Cobb angle to a satisfactory degree. The mean error for the Cobb angle is still too high for this measurement to be used clinically. ${ }^{31,35,36}$ Works on improving this method and using differential geometry and the triangulation process are underway. According to Harzmann et al, ${ }^{28}$ due to the use of surface topography, it is possible to detect even small postural and spinal defects that are not visible in X-ray. ${ }^{28}$ The results of the surface topography test showed high sensitivity and good reliability, which, however, also depend on the experience and qualifications of the person performing the test. ${ }^{28}$ In more serious cases, radiological control is by no means superfluous, to the contrary, it remains the gold standard for confirming the diagnosis made during initial medical examinations and surface topography. This especially applies to scoliosis in children and adolescents during growth spurts, where it is important to determine the degree of deformation and determine the progression of curvature and ossification level (Risser Test). ${ }^{28}$ Also, our several years of observations and studies on 5000 children allow to confirm that the Diers formetric III 4D increases the angle of curvature of the spine and does not always coincide with the Cobb angle test visible in X-ray. ${ }^{10}$ The creators of the surface topography method are aware of this, and therefore, recommend the criterion of assuming 3 parameters corresponding with the X-ray examination to determine scoliotic changes. The occurrence of scoliotic posture and scoliosis was found by considering the values of 3 variables: pelvic tilt $(\mathrm{mm})$, lateral deviation $(\mathrm{mm})$ and surface rotation $\left({ }^{\circ}\right)$. The following division was adopted for the assessment of: scoliotic posture - pelvic tilt less than $5 \mathrm{~mm}$, lateral deviation (rms) less than $5 \mathrm{~mm}$, rotation (rms) less than $5^{\circ}$; scoliosis: pelvic tilt equal to or greater than $5 \mathrm{~mm}$, lateral deviation (rms) equal to or greater than $5 \mathrm{~mm}$, rotation (rms) equal to or greater than $5^{\circ}$. To assess the presence of scoliotic posture or scoliosis, all 3 conditions had to be met. If the 3 requirements were not met, it was assumed that scoliosis or scoliotic posture did not occur. This criterion is reliable and objective, allowing to determine the location, direction and number of spinal curvatures with high precision. The accuracy of the hardware and programming components needed to save and calculate data was created during the years of development. Thus, the measuring points included in the projection lines are determined with to the nearest $0.5 \mathrm{~mm}$ on the surface and $0.1 \mathrm{~mm}$ in depth. The accuracy of the automatic determination of fixed points is approx. $0.8 \mathrm{~mm}$. These values are considered sufficient. ${ }^{30,31,32}$ After examining body posture, the children went to another room, where under supervision, they rested for about 1 hour. At that time, they could sit and draw, watch a cartoon or walk, making sure they did not get tired by, for example, running.

The electromyographic analysis was performed using a 14-channel Noraxon TeleMyo DTS apparatus. Noraxon had the software version - MR3 myoMuscle Essential, which enables saving, exporting and analysing using a ready report template. The device was EC certified (Certificate Production Quality Assurance Directive 93/ 42/EEC Medical Devices Annex V). The product complied with the Medical Devices Directive 93/42/EEC requirements for class I products. It had the appropriate $\mathrm{CE}$ mark. The product complied with the definition of Class I devices and the standard product. Safety: IEC 60601-1 (1988) and EMC: IEC 60601-1-2. ${ }^{37}$ The erector spinae muscle was examined in the thoracic and lumbar sections, both on the left and right sides, at the top of the curvature (approximately at the height of $\mathrm{T}$ 5-6 and L 2-3). Before the examination, the skin was cleaned with abrasive liquid at the points where the electrodes were applied, so as to obtain resistance between the skin and the electrode below $2 \mathrm{k} \Omega .{ }^{37}$ The electrodes were located parallel to the direction of the tested muscle fibres. ${ }^{38}$ The distance between them was about two centimetres. In the study, we used electrodes recommended for children and infants, gelled sensor: $\mathrm{Ag} / \mathrm{AgCl}$; type: $\mathrm{ES}$ 
GS30; manufacturer: ESVICO Poland; base: sponge; gel: solid, shape: round, size: $30 \mathrm{~mm}$ in diameter. Application was carried out by electrodes being placed on the skin. ${ }^{39}$ First, a raw signal appeared on the computer screen which proceeded the target recording of the potential. Depending on the type of EMG, the EMG band frequency range was within 10 to $500 \mathrm{~Hz}^{40}$ The most important mechanisms affecting the size and density of the signal are the recruitment of MUAP (motor unit action potential) and their frequency of discharges. These are the main mechanisms that control the contraction process and modulate muscle strength. Since human connective tissue and integument are a low-permeable filter for the original signal, the frequency directly analysed reflects the recruitment and discharge characteristics in the motor units of the muscle being examined. In accordance with the recommendations for scientific work (ISEK, SENIAM), we did not use any hardware filters (eg cut-off filters) in the EMG records, except for band filters in the amplifier $(10-500 \mathrm{~Hz})$ which are necessary to avoid anti-aliasing in sampling. ${ }^{41}$ Only the algorithm of the signal processed using the Root Mean Square $100 \mathrm{~ms}$ filter was used in order to assure a cleaned and easy to read signal. This filter reflects the main strength of the signal and is recommended to smooth the record. ${ }^{37}$ At any given time, even after signal processing, it was possible to return to the raw EMG recording. The unregulated EMG signal recorded on the skin was characterised by typical discharges from a few to $2-3 \mathrm{mV}$. Signal fluctuations were minimised via the use of digital smoothing algorithms that highlighted the main direction in which the signal proceeds. Excessive frequency peaks have been cut so that the resulting signal is linearized. The recording, in the form of the square root mean (RMS), smoothed in this way, reflected the main signal strength. ${ }^{37}$ Before the computer could analyse the EMG signal and display it on the monitor, it was converted from analogue to digital (A/D conversion). Averaging such repetitions required a standardised time format. It consisted in separating all repetitions in a given sequence into an equal number of periods for which a separate average value was calculated. The original time scale in (milli-) seconds was converted to cycle percentages in the range of 0 to $100 \%{ }^{37}$ The division into 100 was used and the measurement was converted to the whole 10 seconds at a time. According to ISEK and SENIAM guidelines, the study contained information on: the shape, size, and material of the electrodes, skin cleanser, distance and placement of electrodes, and the type of algorithm used. In Poland, the frequency is $50 \mathrm{~Hz} / 230 \mathrm{~V}$ (Polish Standard PN-IEC 60038). The permissible deviations are $\pm 10 \%$, ie 45 to $55 \mathrm{~Hz}(207$ to $253 \mathrm{~V}){ }^{41}$ Each of the trials lasted 10 seconds. Then, using the Noraxon TeleMyo DTS programme, the erector spinae was selected for analysis. The results of the test took the scale of the voltage intensity in the time interval into account, which was 100 milliseconds. ${ }^{37}$ The assessment of the relationship between the SEMG frequency of the spine extensor and the location, direction and number of spinal curvatures required 16 SEMG measurements. SEMG frequencies were recorded from the erector spinae in the thoracic and lumbar sections on the right and left side of the spine, at the curvature apex in the following positions: standing position, prone position, prone, position, trunk up, prone position, lower limbs up. First, the SEMG frequency test was performed in a standing position. The subject stood in a relaxed, habitual position. Secondly, measurements were taken in prone position. The subject lay freely on his/her stomach. The lower legs were extended and the upper limbs were placed along the trunk. The third measurements were taken in the position: trunk up. Examined from supine position (lower limbs extended in the knee joints, upper limbs arranged along the trunk, the pelvis stabilized), the trunk was lifted within the mobility of the lumbar spine (about $30^{\circ}$ ), then maintained in this position for $10 \mathrm{~s}$ of the test. The fourth measurements were taken with the lower limbs directed upwards and in prone position. From this position, with the upper trunk stabilised (shoulders and chest, limbs arranged as before), the subject lifted both lower limbs within the mobility of the hip joints (about $15^{\circ}$ ) for 10 seconds of the test. A total of 16 SEMG frequency measurements of the erector spinae were performed: standing position, thoracic segment, left side; standing position, thoracic segment, right side; standing position lumbar section, left side; standing position, lumbar section, right side; prone position, thoracic segment, left side; prone position, thoracic segment, right side; prone position, lumbar segment, left side; prone position, lumbar section, right side; prone, position, trunk up, thoracic segment, left side; prone, position, trunk up, thoracic segment, right side; prone position, trunk up, lumbar section, left side; prone position, trunk up, lumbar section, right side; prone position, lower limbs up, thoracic segment, left side; prone position, lower limbs up, thoracic segment, right side; prone position, lower limbs up, lumbar section, left side; prone position, lower limbs up, lumbar section, right side. Then, SEMG examination of the erector spinae was 
performed, which lasted about 30 minutes. There was a 60-second interval between SEMG tests performed in various positions. The SEMG frequency is generally used to assess the degree of activity and the strength of muscle contraction and fatigue. However, in our research, the test time was short, ie 10 seconds, and did not lead to high muscle fatigue. That is why we did not analyse the SEMG frequency more extensively for erector spinae fatigue. SEMG measurement was in line with the SENIAM (Surface ElectroMyoGraphy for the Non-Invasive Assessment of Muscles) recommendations, a European research programme containing a number of guidelines on the selection of electrode types, their location, anatomy and muscle function, muscle group tests, signal processing and hardware conditions. ${ }^{38}$ Both postural examination and SEMG frequency analysis were painless and non-invasive.

\section{Statistical Analysis}

In order to determine the normality of variable distribution, the Kolmogorov-Smirnov test was performed. To assess most important and statistically significant predictors for dependent variables: the location, direction and number of spinal curvatures and the independent variable, ie the SEMG frequency of the erector, the multinomial, stepwise and progressive regression models were used:

$$
\mathrm{Y}=\mathrm{a}+\mathrm{b}_{1} \mathrm{X}_{1}+\mathrm{b}_{2} \mathrm{X}_{2}+\ldots+\mathrm{b}_{\mathrm{n}} \mathrm{X}_{\mathrm{n}}
$$

The incoming data consisted of the following 16 independent variables: standing position, thoracic segment, left side; standing position, thoracic segment, right side; standing position lumbar segment, left side; standing position, lumbar segment, right side; prone position, thoracic segment, left side; prone position, thoracic segment, right side; prone position, lumbar segment, left side; prone position, lumbar segment, right side; prone, position, trunk up, thoracic segment, left side; prone, position, trunk up, thoracic segment, right side; prone position, trunk up, lumbar segment, left side; prone position, trunk up, lumbar segment, right side; prone position, lower limbs up, thoracic segment, left side; prone position, lower limbs up, thoracic segment, right side; prone position, lower limbs up, lumbar segment, left side; prone position, lower limbs up, lumbar segment, right side. The verifying parameter used to assess the created models was the determination coefficient (adjusted R-square), as well as test statistics and the level of statistical significance, which clearly allowed to choose models with the assumed level of statistical significance of $p<0.05$.

\section{Results}

The study group included 103 (42.21\%) children with scoliosis and $141(57.79 \%)$ with scoliotic posture. In the group of children with scoliosis, the most common was curvature in the thoracic segment. In girls, this was (62\%), in boys $(56 \%)$. In the group of children with scoliotic posture, the thoracic location of the curvature was also most common, in girls (49\%) and boys (45\%). The leftsided curvatures were most common among girls, both in the scoliosis (41\%) and scoliotic posture groups. On the other hand, right-sided curvature prevailed in boys. The most common were single curvatures, among girls in the scoliosis group $(77 \%)$ and in the group with scoliotic posture (63\%), among boys in the scoliosis group (56\%) and in those with scoliotic posture $(52 \%)$. There were no triple curvatures (Table 1).

The greatest absolute differentiation in SEMG frequency among girls from the scoliosis group occurred in the test: prone position, lumbar segment, left side $(\mathrm{SD}=36.99)$, while in the scoliotic posture group, this occurred in the following test: prone position, lower limbs up, lumbar segment, right side $(\mathrm{SD}=37.5)$; however, in boys, both in the scoliosis $(\mathrm{SD}=40.54)$ as well as the scoliotic posture group $(\mathrm{SD}=35.37)$, this occurred in the test: prone position, lower limbs up, lumbar segment, right side. In the case of girls, the greatest generalised frequency was visible in scoliotic posture $($ Mean $=73.69 \mathrm{~Hz}$ ), while among boys, in the case of scoliosis $($ Mean $=79.75 \mathrm{~Hz})($ Tables 2 and 3).

\section{Location of Spinal Curvature and SEMG Frequency of Erector Spinae}

There was a significant correlation between the curvature location and the SEMG frequency of the erector spinae both in the scoliosis and the scoliotic posture groups. In scoliosis (SG), statistically significant model predictors were the frequencies tested in: prone position, lower limbs up, thoracic segment, right side $(p=0.02)$ and in prone position, lumbar segment, right side $(p=0.01)$. The model explained $41 \%$ of the total variability $\left(R^{2}=0.41\right)$, which indicates a low fit to the data, but the assumed level of statistical significance $(p=0.003)$ was met. Furthermore, the appropriate value of the statistical test $\mathrm{F}=3.87$ was obtained (Table 4). The model assumed the form:

$\mathrm{Y}_{(\text {LC-SEMG_FES-SG) }}=2.74+0.01 *$ prone position, lower limbs up, thoracic segment, right side $+0.01 *$ prone position, lumbar segment, right side 
Table I Location, Direction and Number of Spinal Curvatures

\begin{tabular}{|l|c|c|c|c|}
\hline \multicolumn{4}{|c|}{ Curvature Location in Girls } \\
\hline Curvature Location & \multicolumn{2}{|c|}{ Scoliosis } & \multicolumn{2}{c|}{ Scoliotic Posture } \\
\cline { 2 - 5 } & $\mathrm{N}$ & $\%$ & $\mathrm{~N}$ & $\%$ \\
\hline Thoracic & 24 & 62 & 34 & 49 \\
\hline Thoracolumbar & 8 & 21 & 24 & 34 \\
\hline Lumbar & 7 & 18 & 12 & 17 \\
\hline
\end{tabular}

\begin{tabular}{|l|c|c|c|c|}
\hline \multicolumn{4}{|c|}{ Curvature Location in Boys } \\
\hline \multirow{2}{*}{ Curvature Location } & \multicolumn{2}{|c|}{ Scoliosis } & \multicolumn{2}{c|}{ Scoliotic Posture } \\
\cline { 2 - 5 } & $\mathrm{N}$ & $\%$ & $\mathrm{~N}$ & $\%$ \\
\hline Thoracic & 36 & 56 & 32 & 45 \\
\hline Thoracolumbar & 19 & 30 & 26 & 37 \\
\hline Lumbar & 9 & 14 & 13 & 18 \\
\hline
\end{tabular}

\begin{tabular}{|l|c|c|c|c|}
\hline \multicolumn{4}{|c|}{ Curvature direction in girls } \\
\hline Curvature direction & \multicolumn{2}{|c|}{ Scoliosis } & \multicolumn{2}{c|}{ Scoliotic posture } \\
\cline { 2 - 5 } & $\mathrm{N}$ & $\%$ & $\mathrm{~N}$ & $\%$ \\
\hline Left-sided & 16 & 41 & 23 & 33 \\
\hline Right-sided & 14 & 36 & 21 & 30 \\
\hline Right-/left-sided & 3 & 8 & 6 & 9 \\
\hline Left-/right-sided & 6 & 15 & 20 & 29 \\
\hline
\end{tabular}

Curvature direction in boys

\begin{tabular}{|l|c|c|c|c|}
\hline \multirow{2}{*}{ Curvature direction } & \multicolumn{2}{|c|}{ Scoliosis } & \multicolumn{2}{c|}{ Scoliotic posture } \\
\cline { 2 - 5 } & $\mathrm{N}$ & $\%$ & $\mathrm{~N}$ & $\%$ \\
\hline Left-sided & 18 & 28 & 18 & 25 \\
\hline Right-sided & 18 & 28 & 20 & 28 \\
\hline Right-/left-sided & 5 & 8 & 15 & 21 \\
\hline Left-/right-sided & 23 & 36 & 18 & 25 \\
\hline
\end{tabular}

Number of curvatures in girls

\begin{tabular}{|l|c|c|c|c|}
\hline \multirow{2}{*}{$\begin{array}{l}\text { Number of } \\
\text { curvatures }\end{array}$} & \multicolumn{2}{|c|}{ Scoliosis } & \multicolumn{2}{c|}{ Scoliotic posture } \\
\cline { 2 - 5 } & $\mathrm{N}$ & $\%$ & $\mathrm{~N}$ & $\%$ \\
\hline One & 30 & 77 & 44 & 63 \\
\hline Two & 9 & 23 & 26 & 37 \\
\hline
\end{tabular}

Number of curvatures in boys

\begin{tabular}{|l|c|c|c|c|}
\hline \multirow{2}{*}{$\begin{array}{l}\text { Number of } \\
\text { curvatures }\end{array}$} & \multicolumn{2}{|c|}{ Scoliosis } & \multicolumn{2}{c|}{ Scoliotic posture } \\
\cline { 2 - 5 } & $\mathrm{N}$ & $\%$ & $\mathrm{~N}$ & $\%$ \\
\hline
\end{tabular}

(Continued)
Table I (Continued).

\begin{tabular}{|l|l|l|l|l|}
\hline One & 36 & 56 & 37 & 52 \\
\hline Two & 28 & 44 & 34 & 48 \\
\hline
\end{tabular}

Table 2 SEMG Frequency of the Erector Spinae in Girls $(\mathrm{Hz})$

\begin{tabular}{|c|c|c|c|c|}
\hline \multirow[t]{2}{*}{ Variables } & \multicolumn{2}{|c|}{ Scoliosis } & \multicolumn{2}{|c|}{$\begin{array}{l}\text { Scoliotic } \\
\text { Posture }\end{array}$} \\
\hline & Mean & SD & Mean & SD \\
\hline $\begin{array}{l}\text { Standing position, thoracic } \\
\text { segment, left side }\end{array}$ & 52.84 & 26.36 & 54.44 & 25.68 \\
\hline $\begin{array}{l}\text { Standing position, thoracic } \\
\text { segment, right side }\end{array}$ & 55.61 & 27.92 & 62.77 & 26.62 \\
\hline $\begin{array}{l}\text { Standing position lumbar } \\
\text { segment, left side }\end{array}$ & 83.92 & 32.97 & 84.77 & 33.83 \\
\hline $\begin{array}{l}\text { Standing position, lumbar } \\
\text { segment, right side }\end{array}$ & 63.15 & 29.99 & 55.76 & 25.35 \\
\hline $\begin{array}{l}\text { Prone position, thoracic } \\
\text { segment, left side }\end{array}$ & 59.16 & 25.83 & 62.59 & 25.17 \\
\hline $\begin{array}{l}\text { Prone position, thoracic } \\
\text { segment, right side }\end{array}$ & 63.30 & 27.28 & 71.18 & 23.67 \\
\hline $\begin{array}{l}\text { Prone position, lumbar segment, } \\
\text { left side }\end{array}$ & 72.60 & 36.99 & 73.75 & 35.03 \\
\hline $\begin{array}{l}\text { Prone position, lumbar segment, } \\
\text { right side }\end{array}$ & 46.65 & 24.95 & 47.77 & 23.40 \\
\hline $\begin{array}{l}\text { Prone, position, trunk up, } \\
\text { thoracic segment, left side }\end{array}$ & 82.46 & $|5.7|$ & 82.17 & 17.66 \\
\hline $\begin{array}{l}\text { Prone, position, trunk up, } \\
\text { thoracic segment, right side }\end{array}$ & 82.09 & 15.06 & 83.19 & 17.38 \\
\hline $\begin{array}{l}\text { Prone position, trunk up, } \\
\text { lumbar segment, left side }\end{array}$ & 109.30 & 12.62 & 108.39 & 19.77 \\
\hline $\begin{array}{l}\text { Prone position, trunk up, } \\
\text { lumbar segment, right side }\end{array}$ & 88.92 & 33.47 & 84.75 & 33.09 \\
\hline $\begin{array}{l}\text { Prone position, lower limbs up, } \\
\text { thoracic segment, left side }\end{array}$ & 61.76 & 19.32 & 65.78 & 19.09 \\
\hline $\begin{array}{l}\text { Prone position, lower limbs up, } \\
\text { thoracic segment, right side }\end{array}$ & 66.86 & 18.56 & 71.03 & 19.53 \\
\hline $\begin{array}{l}\text { Prone position, lower limbs up, } \\
\text { lumbar segment, left side }\end{array}$ & 107.56 & $|7.5|$ & 106.00 & 28.16 \\
\hline $\begin{array}{l}\text { Prone position, lower limbs up, } \\
\text { lumbar segment, right side }\end{array}$ & 82.88 & 35.77 & 85.10 & 37.50 \\
\hline
\end{tabular}


Table 3 SEMG Frequency of the Erector Spinae in Boys $(\mathrm{Hz})$

\begin{tabular}{|c|c|c|c|c|}
\hline \multirow[t]{2}{*}{ Variables } & \multicolumn{2}{|c|}{ Scoliosis } & \multicolumn{2}{|c|}{$\begin{array}{l}\text { Scoliotic } \\
\text { Posture }\end{array}$} \\
\hline & Mean & SD & Mean & SD \\
\hline $\begin{array}{l}\text { Standing position, thoracic } \\
\text { segment, left side }\end{array}$ & 58.13 & 23.66 & 53.87 & 24.59 \\
\hline $\begin{array}{l}\text { Standing position, thoracic } \\
\text { segment, right side }\end{array}$ & 65.39 & 23.51 & 60.47 & 25.20 \\
\hline $\begin{array}{l}\text { Standing position lumbar } \\
\text { segment, left side }\end{array}$ & 92.67 & 31.16 & 97.59 & 27.32 \\
\hline $\begin{array}{l}\text { Standing position, lumbar } \\
\text { segment, right side }\end{array}$ & 65.59 & 27.99 & 67.65 & 27.87 \\
\hline $\begin{array}{l}\text { Prone position, thoracic } \\
\text { segment, left side }\end{array}$ & 64.59 & 27.70 & 57.19 & 26.06 \\
\hline $\begin{array}{l}\text { Prone position, thoracic } \\
\text { segment, right side }\end{array}$ & 75.42 & 24.30 & 68.63 & 23.00 \\
\hline $\begin{array}{l}\text { Prone position, lumbar segment, } \\
\text { left side }\end{array}$ & 72.50 & 36.54 & 67.88 & 33.10 \\
\hline $\begin{array}{l}\text { Prone position, lumbar segment, } \\
\text { right side }\end{array}$ & 48.55 & 26.15 & 40.81 & 20.22 \\
\hline $\begin{array}{l}\text { Prone, position, trunk up, } \\
\text { thoracic segment, left side }\end{array}$ & 87.27 & 11.68 & 86.38 & 14.54 \\
\hline $\begin{array}{l}\text { Prone, position, trunk up, } \\
\text { thoracic segment, right side }\end{array}$ & 88.95 & 14.72 & 85.04 & 13.80 \\
\hline $\begin{array}{l}\text { Prone position, trunk up, } \\
\text { lumbar segment, left side }\end{array}$ & 116.68 & 17.13 & 114.38 & 15.63 \\
\hline $\begin{array}{l}\text { Prone position, trunk up, } \\
\text { lumbar segment, right side }\end{array}$ & 94.17 & 36.85 & 93.76 & 33.05 \\
\hline $\begin{array}{l}\text { Prone position, lower limbs up, } \\
\text { thoracic segment, left side }\end{array}$ & 68.00 & 15.29 & 67.77 & 17.19 \\
\hline $\begin{array}{l}\text { Prone position, lower limbs up, } \\
\text { thoracic segment, right side }\end{array}$ & 75.03 & 18.06 & 72.96 & 16.97 \\
\hline $\begin{array}{l}\text { Prone position, lower limbs up, } \\
\text { lumbar segment, left side }\end{array}$ & II4.II & 23.25 & 116.02 & 17.83 \\
\hline $\begin{array}{l}\text { Prone position, lower limbs up, } \\
\text { lumbar segment, right side }\end{array}$ & 89.07 & 40.54 & 93.37 & 35.37 \\
\hline
\end{tabular}

The most important predictor for $\mathrm{Y}$ in scoliosis group (SG) was prone position, lumbar segment, right-side variable (Beta value).

In the group with scoliotic posture (SPG), the most important and statistically significant model predictors were the tests: prone position, trunk up, lumbar segment, right side $(p=0.01)$, and left side $(p=0.01)$; standing position, thoracic segment,
Table 4 Model of Forward Stepwise Regression for the Location of Curvature and SEMG Frequency of the Erector Spinae (LCSEMG_FES)

\begin{tabular}{|c|c|c|c|}
\hline \multicolumn{4}{|l|}{ Scoliosis Group } \\
\hline Variable & Beta & b & $\mathbf{p}$ \\
\hline Constant/absolute term & & 2.74 & 0.001 \\
\hline $\begin{array}{l}\text { Prone position, lower limbs up, thoracic } \\
\text { segment, right side }\end{array}$ & 0.28 & 0.01 & 0.02 \\
\hline Prone position, lumbar segment, right side & 0.40 & 0.01 & 0.01 \\
\hline \multicolumn{4}{|c|}{$R^{2}=0.4 \mathrm{I} ; \mathrm{F}(5.97)=3.87, p=0.003$} \\
\hline \multicolumn{4}{|c|}{ Scoliotic posture group } \\
\hline Variable & Beta & b & $\mathbf{p}$ \\
\hline Constant/absolute term & & 2.30 & 0.001 \\
\hline $\begin{array}{l}\text { Prone position, trunk up, lumbar segment, } \\
\text { right side }\end{array}$ & -0.35 & -0.01 & 0.01 \\
\hline $\begin{array}{l}\text { Standing position, thoracic segment, right } \\
\text { side }\end{array}$ & -0.39 & -0.01 & 0.01 \\
\hline $\begin{array}{l}\text { Prone position, trunk up, lumbar segment, } \\
\text { left side }\end{array}$ & 0.49 & 0.01 & 0.01 \\
\hline $\begin{array}{l}\text { Prone position, lower limbs up, lumbar } \\
\text { segment, right side }\end{array}$ & -0.48 & -0.01 & 0.04 \\
\hline \multicolumn{4}{|c|}{$R^{2}=0.34 ; F(8.132)=2.14, p=0.04$} \\
\hline
\end{tabular}

right side $(p=0.01)$; prone position, lower limbs up, lumbar segment, right side $(p=0.04)$. The model was explained only in $34 \%\left(\mathrm{R}^{2}=0.34\right)$, ie less than half, but the assumed level of statistical significance $(p=0.04)$ was also met, and the appropriate value of the statistical test $\mathrm{F}=2.14$ was obtained (Table 4).

The model assumed the form: $\mathrm{Y}_{\text {(LC-SEMG_FES-SPG) }}{ }^{1}$ ( ${ }^{1}$ Location of spinal curvature; SEMG frequency; group scoliotic posture.) $=2.30-0.01 *$ prone position, trunk up, lumbar segment, left side -0.01 *standing position, thoracic segment, right side $+0.01 *$ prone position, trunk up, lumbar segment, left side -0.01 * prone position, lower limbs up, lumbar segment, right side.

The most important predictors for $\mathrm{Y}$ in scoliotic posture (SPG) was prone position, trunk up, lumbar segment, left-side variable (Beta value).

\section{Direction of Spinal Curvature and SEMG Frequency of Erector Spinae}

The most important and statistically significant model predictors for the SEMG frequency of the erector spinae and the 
direction of spinal curvature in the scoliosis group (SG) was the test: prone position, position, trunk up, thoracic segment, left side ( $\mathrm{p}=0.03$ ) and: prone position, lower limbs up, lumbar segment, left side $(p=0.01)$. The model explained by the independent variables adopted in the model accounts for $39 \%$ of the total variability $\left(\mathrm{R}^{2}=0.39\right)$, which indicates a low fit to the data, but the assumed level of statistical significance $(p=0.01)$ was met, and the appropriate value of the statistical test $\mathrm{F}=2.98$ was obtained (Table 5). However, in the scoliotic posture group (SPG), the most important and statistically significant model predictor was the SEMG frequency tested in: prone position, trunk up, lumbar segment, left side test $(\mathrm{p}=0.04)$. The model was explained only in $29 \%$ $\left(\mathrm{R}^{2}=0.29\right)$, which was low, but the assumed level of statistical significance $(\mathrm{p}=0.04)$ was also met, and the appropriate statistical test value $\mathrm{F}=2.43$ was obtained (Table 5). The models assumed the form:

$\mathrm{Y}_{\text {(DC-SEMG_FES -SG) }}{ }^{2}\left({ }^{2}\right.$ Direction of curvature; SEMG frequency; Scoliosis group.) $=1.06+0.02 *$ prone, position, trunk up, thoracic segment, left side- $0.01 *$ prone position, lower limbs up, lumbar segment, left side

$\mathrm{Y}_{\text {(DC-SEMG_FES -SPG) }}=1.99-0.01$ * prone, position, trunk up, thoracic segment, left side

The most important predictor for $\mathrm{Y}$ in scoliosis group (SG) was prone position, lower limbs up, lumbar segment,

Table 5 Model of Forward Stepwise Regression for the Direction of Curvature and SEMG Frequency of the Erector Spinae (DC-SEMG_FES)

\begin{tabular}{|c|c|c|c|}
\hline \multicolumn{4}{|l|}{ Scoliosis Group } \\
\hline Variable & Beta & b & $\mathbf{p}$ \\
\hline Constant/absolute term & & 1.06 & 0.17 \\
\hline $\begin{array}{l}\text { Prone, position, trunk up, thoracic } \\
\text { segment, left side }\end{array}$ & 0.23 & 0.02 & 0.03 \\
\hline $\begin{array}{l}\text { Prone position, lower limbs up, lumbar } \\
\text { segment, left side }\end{array}$ & -0.31 & -0.01 & 0.01 \\
\hline \multicolumn{4}{|c|}{$R^{2}=0.39 ; F(6.96)=2.98, p=0.01$} \\
\hline \multicolumn{4}{|c|}{ Scoliotic posture group } \\
\hline Variable & Beta & b & $\mathbf{p}$ \\
\hline Absolute/constant term & & 1.99 & 0.001 \\
\hline $\begin{array}{l}\text { Prone position, trunk up, lumbar segment, } \\
\text { left side }\end{array}$ & -0.26 & -0.01 & 0.04 \\
\hline \multicolumn{4}{|c|}{ Prone position, trunk up, lumbar segment, left side } \\
\hline
\end{tabular}

left-side variable and prone, position, trunk up, thoracic segment, left side in scoliotic posture group (SPG) (Beta value).

\section{Number of Spinal Curvature and SEMG Frequency of Erector Spinae}

The most important and statistically significant model predictors for the SEMG frequency of the erector spinae and the number of curvatures in the scoliosis group (SG) were in the case of: prone position, trunk up, thoracic segment, left side ( $p=0.01)$; prone position, trunk up, lumbar segment, right side $(p=0.02)$; standing position, thoracic segment, right side $(p=0.01)$ (Table 6$)$. The model explained by the independent variables adopted in the model accounts for $37 \%$ of the total variability $\left(\mathrm{R}^{2}=0.37\right)$, which indicates a low fit to the data, but the assumed level of statistical significance $(p=0.03)$ was met, and the appropriate value of the $\mathrm{F}$ statistical test was obtained $=2.5$. In scoliotic posture group (SPG), the most important and statistically significant model predictor was the test: prone position, lower limbs up, thoracic segment, left side $(p=0.03$ ) (Table 6$)$. The model was explained only in $18 \%\left(\mathrm{R}^{2}=0.18\right)$, ie less than half, but the assumed level of statistical significance $(p=0.03)$ was also met, and the appropriate value of the statistical test $\mathrm{F}=4.58$ was obtained (Table 6). The models assumed the form:

Table 6 Forward Stepwise Regression Model for the Number of Curvature (NC)

\begin{tabular}{|c|c|c|c|}
\hline \multicolumn{4}{|c|}{ Scoliosis Group } \\
\hline Variable & Beta & b & $\mathbf{p}$ \\
\hline Constant/absolute term & & 0.46 & 0.30 \\
\hline $\begin{array}{l}\text { Prone, position, trunk up, thoracic } \\
\text { segment, left side }\end{array}$ & 0.28 & 0.01 & 0.01 \\
\hline $\begin{array}{l}\text { Prone position, trunk up, lumbar } \\
\text { segment, right side }\end{array}$ & -0.37 & -0.01 & 0.02 \\
\hline $\begin{array}{l}\text { Standing position, thoracic segment, } \\
\text { right side }\end{array}$ & -0.39 & -0.01 & 0.01 \\
\hline \multicolumn{4}{|c|}{$\mathrm{R}^{2}=0.37 ; \mathrm{F}(6.96)=2.5, p=0.03$} \\
\hline \multicolumn{4}{|c|}{ Scoliotic posture group } \\
\hline Variable & Beta & b & $\mathbf{p}$ \\
\hline Constant/absolute term & & 1.10 & 0.001 \\
\hline $\begin{array}{l}\text { Prone position, lower limbs up, thoracic } \\
\text { segment, left side }\end{array}$ & 0.18 & 0.01 & 0.03 \\
\hline \multicolumn{4}{|c|}{$R^{2}=0.18 ; F(I .139)=4.58, p=0.03$} \\
\hline
\end{tabular}


$\mathrm{Y}_{\left(\mathrm{NC}-\mathrm{SEMG} \_\mathrm{FES}-\mathrm{SG}\right)}=0.46+0.01 *$ prone, position, trunk up, thoracic segment, left side -0.01 * prone position, trunk up, lumbar segment, right side -0.01 *standing position, thoracic segment, right side

$\mathrm{Y}_{\left(\mathrm{NC}-\mathrm{SEMG} \_\mathrm{FES}-\mathrm{SPG}\right)}=1.10+0.01 *$ prone position, lower limbs up, thoracic segment, left side

The most important predictor for $\mathrm{Y}$ in SG were standing position, thoracic segment, right-side variable and prone position, lower limbs up, thoracic segment, left side in SPG (Beta value).

\section{Discussion}

In our study among school-children, thoracic location of the curvatures was most common. In the group of girls, left-sided thoracic scoliosis slightly prevailed. This is explained by the fact that in the whole studied group, low-grade scoliosis not exceeding $30^{\circ}$ prevailed. ${ }^{42}$ There is information in the literature that in low-grade scoliosis, left-sided scoliosis $(63.0 \%)$ is more common than rightsided scoliosis (37.0\%). ${ }^{9}$ Only in curvatures above $30^{\circ}$ do right-sided curvatures prevail. ${ }^{9}$ These types of scoliosis are more often double-curvatures, related to compensation, thoracic right and lumbar left. ${ }^{9}$ These curvatures have the worst prognosis and sometimes require surgery. Also, in curvatures appearing before the age of 3 , the primary convexity is located in part in the thoracic segment and is usually left-sided. Double curvatures are less common. ${ }^{9}$ In our research, we have demonstrated a significant relationship between location, direction number of spinal curvatures and the SEMG frequency of the erector spinae. Among the concepts regarding the formation and development of idiopathic scoliosis, the theory of muscle tension imbalance occupies a special position. ${ }^{21}$ In theory, these disorders are secondary to yet unstudied changes occurring in the central nervous system. However, muscle disturbances are preceded by structural changes in the bones such as wedging, rotation and torsion of the vertebrae. ${ }^{43}$ They can cause a set of changes forming a clinical and anatomopathological image of scoliosis. In many studies, the key importance of the CNS in the pathogenesis of scoliosis is indicated. ${ }^{44}$ Thanks to the development of diagnostic imaging methods, it is possible to thoroughly examine the structures of the nervous system.

Joly et $\mathrm{a}^{45}$ hypothesized that the corpus callosum body differs in the microstructure of white matter in patients with idiopathic scoliosis compared to those healthy. With the help of DTI (Diffusion Tensor Imaging), brain imaging was performed (Fractional Anisotropy) in 10 subjects with idiopathic scoliosis and 49 healthy people forming a control group. Patients with right-sided curvatures in the thoracic or thoracolumbar region with a Cobb angle of $\geq 15^{\circ}$ were qualified for the study. Statistically significantly lower FA in the brainstem was found among individuals with scoliosis, compared to the control group. ${ }^{45}$ Liu et $\mathrm{al}^{46}{ }^{46}$ in their research, noted the occurrence of a larger corpus callosum in people with right-sided idiopathic scoliosis in the thoracic segment. ${ }^{46}$ In contrast, Wang noted morphometric abnormalities in the corpus callosum in the patients with left-sided idiopathic scoliosis in the thoracic segment. ${ }^{47}$ Subsequent researchers dealing with the role of the sensory system have put forward the thesis that patients with adolescent idiopathic scoliosis AIS - have a more centralised brain organisation, which may promote asymmetrical neurological functioning. ${ }^{48}$ Lo et al, using transcranial electrical stimulation - TES, examined 29 patients with scoliosis. The study group consisted of 15 people with diagnosed adolescent idiopathic scoliosis (AIS) and 14 with adult degenerative scoliosis (ADS). The results showed that in patients with AIS, the average amplitude of MEP (Motor Evoked Potential) was greater on the convex side of curvature. ${ }^{49}$ Domenech, ${ }^{50,51}$ using transcranial magnetic stimulation, showed that patients with scoliosis have significantly reduced cortico-cortical inhibition on the concave side of curvature. He also provided evidence of incorrect, asymmetrical activation of the contralateral additional motor cortex during motor tasks with upper limb activation in patients with idiopathic scoliosis. $^{50,51}$

According to Burwell et al, ${ }^{52}$ properly functioning normal neuro-osseous timing of the maturation system (NOTOM) provides a child with dynamic, physiological and postural balance during growth and adolescence. Two synchronised processes connected by the sensory system and motor skills are responsible for this, the so-called osseous escalator and neural escalator. With proper cooperation of both these systems, the CNS constantly adapts the body to the changing biomechanical and kinetic conditions resulting from skeletal development, coordinating the performance of motor tasks. In the case of juvenile idiopathic scoliosis, both processes are not coordinated, and their course is asymmetrical, which causes the spine to grow rapidly and unevenly. There is also a delay in the development and maturation of the CNS and body schema relative to the skeletal system. Progression, regression or arrest of curvature in scoliosis depends mainly on the degree of dysfunction of central postural control in the 
rapidly growing spine and trunk. Progression of scoliosis may be the result of autonomic nervous system dysfunction. ${ }^{52}$ The described CNS changes in people with scoliosis undoubtedly could have impact on the frequency and amplitude of EMG visible in the recording of contractions and muscle fatigue. Many studies found SEMG abnormalities in idiopathic scoliosis. Riddle and Roaf $^{53}$ and Bayer, ${ }^{54}$ based on research and EMG, came to the conclusion that in idiopathic scoliosis, stronger muscles are always at the apex of the primary curvature. Cassidy et al analysed the role of erector spinae muscles in the pathogenesis of idiopathic scoliosis during gait using EMG. Of the 10 patients examined, 6 of the EMG frequencies were higher on the convex side of the curvature. ${ }^{55}$ Farahpour et $\mathrm{a}^{56}$ performed EMG testing in patients with scoliosis, in which they found a relationship between spinal curvature and uneven tension of the erector spinae muscles. ${ }^{56}$ Stetkarova et $\mathrm{al}^{57}$ noted higher amplitude EMG activity in the paravertebral muscles and changes in muscle fibres on the convex side of the spine. ${ }^{57}$ Guo et al ${ }^{58}$ showed the decreased EMG activity on the concave side of the paraspinal muscles at rest. ${ }^{58}$ Elattar et $\mathrm{al}^{59}$ showed a correlation between the increase in EMG frequency of the erector on the convex side and the progressive increase in the curvature angle on the amplitude and frequency of the EMG record. ${ }^{59}$ Thouin $^{60}$ performed electromyographic testing among patients, considering the division into those with scoliosis and scoliotic posture. He noted higher values of amplitude and frequency EMG signals in patients with scoliotic posture on the concave side, while in those suffering from scoliosis, these increased values were noted on the convex side. ${ }^{60}$ Trontelj et al ${ }^{61}$ studied segmental spinal reflexes (stretch reflexes) in patients with diagnosed scoliosis. They showed that the proprioceptive response to phase stretching of the paravertebral muscles was asymmetrical in all subjects. Based on the data obtained, they hypothesised that segmental, neurogenic disorders, occurring mainly in the deep paravertebral muscles on the side of scoliosis convexity, may contribute to the development of scoliosis. ${ }^{61}$ In other measurements based on the amplitude and frequency EMG analysis, Kwok et $\mathrm{al}^{6}$ stated that not all patients with scoliosis had asymmetrical muscle tension. In some cases, it was evenly distributed. ${ }^{6}$ For scoliosis between $20^{\circ}$ and $50^{\circ}$, Tsai et al ${ }^{62}$ noticed significant asymmetry in the EMG record of the erector spinae muscle in the thoracic spine. During electromyographic examination, scoliosis patients experienced a delay in deep muscle reaction on the convex side of the lumbar region compared to the concave side. ${ }^{62}$ Similar results were achieved by Toosizadeh et al, ${ }^{63}$ in the case of muscles located at the height of the thoracic segment. ${ }^{63}$ In similar studies, positive correlation of Cobb angle with strength of trunk extensors, but not with flexors was observed, and negative correlation with the flexion-extension ratio (F/E value). There was a close relationship between the Cobb angle and the decrease in rotation muscle strength on the convex side to that on the concave side. Median power frequencies in AIS were lower than those in the control, and the difference between right and left sides tended to be large. ${ }^{64}$

In a number of frequency and EMG amplitude studies on the erector spinae, it has been noted that there is a relationship between the development of scoliosis and the activity of these muscles. However, it remains unclear whether changes in the activity of these muscles are primary or secondary in nature, occurring as a result of the body's adaptation to developing scoliosis. A normative reference record of the frequency and EMG amplitude of the postural muscles characteristic for a child with scoliosis will probably be created in the future. Then, based on early EMG studies, it may be possible able to capture initial symptoms of scoliosis and start preventive treatment before irreversible structural changes occur. However, the primary or secondary nature of EMG changes in the erector spinae muscles could be determined by longitudinal examination CNS (PET, RM, DTI). Such research, combined with genetic testing, may explain the origin of idiopathic scoliosis in the future and play an important role in its prevention. ${ }^{65}$ A limitation of the presented study is the lack of a representative group with proper body posture (the norm). In the future, it is recommended to perform SEMG research among a group of children with large scoliosis, ie exceeding $30^{\circ}$.

\section{Conclusions}

There was a significant correlation between the location, direction of and number of curvatures and erector spinae SEMG frequency. The study is of applicative value and fills the gap in research on the frequency of erector spinae SEMG in low-grade scoliosis among small children. Our research is also used in research on the etiology and progression of scoliosis. Visible disturbances in SEMG frequency (activity and tension) of the erector spinae contribute to the development of the curvature 
and testify to the fact that these changes are the primary cause of idiopathic scoliosis. Scoliosis is merely a symptom, an external expression of CNS dysfunction that is not yet fully recognized. It is also visible on the SEMG record of postural muscles. We hope our research will contribute to creating a model record for SEMG of the postural muscles, characteristic for children with scoliosis. Then, based on electromyographic examination, it will be possible to detect the initial symptoms of scoliosis and start preventive rehabilitation before irreversible bone changes start to occur.

\section{Author Contributions}

All authors contributed to data analysis, drafting or revising the article, have agreed on the journal to which the article will be submitted, gave final approval of the version to be published, and agree to be accountable for all aspects of the work.

\section{Funding}

The project is supported within the framework of the programme funded by the Minister of Science and Higher Education under the name "Regional Initiative of Excellence" in 2019-2022, project number: 024/RID/2018/ 19, financing amount: 11,999,000.00 PLN.

\section{Disclosure}

The authors declare no conflict of interest for this work or regarding the publication of this paper.

\section{References}

1. Dupuis S, Fortin C, Caouette C, Leclair I, Aubin CÉ. Global postural re-education in pediatric idiopathic scoliosis: a biomechanical modeling and analysis of curve reduction during active and assisted self-correction. BMC Musculoskelet Disord. 2018;21:191-200. doi:10.1186/s12891-018-2112-9

2. Bruyneel AV, Chavet P, Ebermeyer E, Mesure S. Idiopathic scoliosis: relations between the Cobb angle and the dynamical strategies when sitting on a seesaw. Eur Spine J. 2011;20(2):247-253. doi:10.1007/ s00586-010-1574-8

3. De Sèze M, Cugy E. Pathogenesis of idiopathic scoliosis: a review. Ann Phys Rehabil Med. 2012;1:27.

4. Ko JY, Suh JH, Kim H, Ryu JS. Proposal of a new exercise protocol for idiopathic scoliosis: a Preliminary Study. Medicine (Baltimore). 2018;97(49):e13336. doi:10.1097/MD.0000000000013336

5. Zimmermann CL, Cook TM, Goel VK. Effects of seated posture on erector spinae EMG activity during whole body vibration. Ergonomics. 1993;36(6):667-675. doi:10.1080/00140139308967928

6. Kwok G, Yip J, Cheung MC, Yick KL. Evaluation of myoelectric activity of paraspinal muscles in adolescents with idiopathic scoliosis during habitual standing and sitting. Biomed Res Int. 2015;2015:958450. doi:10.1155/2015/958450

7. Dickson RA, Lawton JD, Archer IA, Butt WP. The pathogenesis of idiopathic scoliosis. J Bont Joint Surg. 1984;668(1):8. doi:10.1302/ 0301-620X.66B1.6693483
8. Lonstein JE, Carlson JM. The prediction of curve progression in untreated idiopathic scoliosis during growth. J Bone Joint Surg. 1984;66A(7):1061. doi:10.2106/00004623-198466070-00013

9. Głowacki M, Kotwicki T, Pucher A. Skrzywienie kręgosłupa. In: Red W, Marciniak A, editors. Wiktora Degi Ortopedia i Rehabilitacja. Szulc, Warszawa: PZWL; 2008.

10. Wilczyński J, Bieniek K. Correlations between somatic features and body posture defects in children aged 10-12. Acta Bioeng Biomech. 2019;1:21. doi:10.5277/ABB-01227-2018-02

11. Feeley I, Hughes A, Cassidy N, Green C. Use of a novel corrective device for correction of deformities in adolescent idiopathic scoliosis. Ir J Med Sci. 2019;189(1):18. doi:10.1007/s11845-019-02031-6

12. James JI. Idiopathic scoliosis; the prognosis, diagnosis, and operative indications related to curve patterns and the age at onset. $J$ Bone Joint Surg Br. 1954;36-B(1):36-49. doi:10.1302/0301-620X.36B1.36

13. Schulthess W. Die Pathologie und Therapie der Ruckgratsverk rummungen. Joachimsthal: Handbuch der Orthopadischen Chirurgie, BD. 1, Abt. 2. Jena: Gustav Fischer; 1905:1905-1907.

14. Lenke LG, Betz RR, Bridwell KH, et al. Intraobserver and interobserver reliability of the classification of thoracic adolescent idiopathic scoliosis. J Bone Joint Surg Am. 1998;80(8):1097-1106. doi:10.2106/ 00004623-199808000-00002

15. Burwell RG, Cole AA, Cook TA, Grivas TB, Kiel AW, Moulton A. Pathogenesis of idiopathic scoliosis. The Nottingham concept. Acta Orthop Belg. 1992;58(1):33-58.

16. Dubousset J, Chopin D, Seringe R. Have we made true progress in surgical indications and determining the limitations of spinal fusion in patients with idiopathic scoliosis? Orthop Traumatol Surg Res. 2018;104(5):555-556. doi:10.1016/j.otsr.2018.07.001

17. Fidler MW, Jowett RL. Muscle imbalance in the aetiology of scoliosis. J Bone Joint Surg Br. 1976;58-B(2):20020. doi:10.1302/ 0301-620X.58B2.932082

18. Donisch EW, Basmajian JV. Electromyography of deep back muscles in man. Am J Anat. 1972;133(1):25-36. doi:10.1002/aja.1001330103

19. Reuber M, Schultz A, McNeill T, Spencer D. Trunk muscle myoelectric activities in idiopathic scoliosis. Spine. 1983;8(5):447-456. doi:10.1097/00007632-198307000-00002

20. Polster J. New data on the correction of scoliosis. Z Orthop Ihre Grenzgeb. 1976;114(4):447-452.

21. Henssge J. Electromyographic contribution to the problem of scoliosis. Z Orthop Ihre Grenzgeb. 1964;99(2):167-195.

22. Kaplan PE, Sahgal V, Hughes R, Kane W, Flanagan N. Neuropathy in thoracic scoliosis. Acta Orthop Scand. 1980;51(2):263-266. doi:10.3109/17453678008990796

23. Viitasalo JHT, Komi PV. Signal characteristics of EMG during fatigue. Eur J Appl Physiol. 1977;37(2):111-121. doi:10.1007/ BF00421697

24. Basmajian JV, De Luca CJ. Muscles Alive: Their Functions Revealed by Electromyography. 5th ed. Baltimore, Maryland: Williams \& Wilkins; 1985.

25. Hoogmartens MJ, Basmajian JV. Asymmetrical postural tone as a possible cause of idiopathic scoliosis. A preliminary communcation. Electromyogr Clin Neurophysiol. 1973;13(3):365-366.

26. Schülein S, Mendoza S, Malzkorn R, Harms J, Skwara A. Rasterstereographic evaluation of interobserver and intraobserver reliability in postsurgical adolescent idiopathic scoliosis patients. J Spinal Disord Tech. 2013;26(4):E143-9. doi:10.1097/BSD.0b013e3 $18281608 \mathrm{c}$

27. Radczuk M, Kasprzak J. Radiation doses received by children during radiographs. Probl Hig Epidemiol. 2014;95(4):956-963.

28. Harzmann H Stellenwert der Videorasterstereografie als schulärztliche Screeningmethode von skoliotischen. Fehlhaltungen und strukturellen Skoliosen. Dissertation. München. Ludwig Maximilians - Universität, Medizinischen Fakultät 2000.

29. Pruijis JEH. The Benefit of School Screening. The Netherlands: Department of Orthopaedics, University of Utrecht; 1985. 
30. Schulte TL, Hierholzer E, Boerke A. Raster stereography versus radiography in the long-term follow-up of idiopathic scoliosis. J Spinal Disord Tech. 2008;21(1):23-28. doi:10.1097/BSD.0b013e $318057529 \mathrm{~b}$

31. Drerup B, Hierholzer E, Frobin W. Oberfächenvermessung bei Wirbelsäulendeformitäten. Vorabdruck anlässlich der 69. Tagung der deutschen Gesellschaft für Orthopädie und Traumatologie. Mainz; 1982.

32. Drerup B, Ellger B, Meyer zu Bentrup FM, Hierholzer E. [Functional rasterstereographic images. A new method for biomechanical analysis of skeletal geometry]. Orthopade. 2001;30(4):242-250. German. doi: $10.1007 / \mathrm{s} 001320050603$

33. Turner-Smith AR, Harris JD, Houghton GR, Jefferson RJ. A method for analysis of back shape in scoliosis. J Biomech. 1988;21 (6):497-509. doi:10.1016/0021-9290(88)90242-4

34. Humbert L, Steffen JS, Vialle R, Dubousset J, Vital JM, Skalli W. 3D analysis of congenital scoliosis due to hemivertebra using biplanar radiography. Eur Spine J. 2013;22(2):379-386. doi:10.1007/s00586-0122539-x

35. Mohokum M. Reproducibility of rasterstereography for kyphotic and lordotic angles and for trunk length and trunk inclination A Reliability Study. Eur Spine J. 2009;18(11):1713.

36. Betsch M, Wild M, Jungbluth $P$, et al. The rasterstereographic-dynamic analysis of posture in adolescents using a modified Matthiass test. Eur Spine J. 2010;19(10):1735-1739. doi:10.1007/s00586-010-1450-6

37. Konrad P; The ABC of EMG. A Practical Introduction to Kinesiological Electromyography Noraxon INC. USA; 2005.

38. Herda TJ, Ryan ED, Kohlmeier M, Trevino MA, Gerstner GR, Roelofs EJ. Examination of muscle morphology and neuromuscular function in normal weight and overfat children aged 7-10 years. Scand J Med Sci Sports. 2018;28(11):2310-2321. doi:10.1111/sms.13256

39. Park JH, Seo KS, Lee SU. Effect of superimposed electromyostimulation on back extensor strengthening: a Pilot Study. J Strength Cond Res. 2016;30(9):2470-2475. doi:10.1519/JSC.0000000000001360

40. Mendes AAMT, de Freitas SMSF, Amorin CF, Cabral CMN, Padula RS. Electromyographic activity of the erector spinae: the short-effect of one workday for welders with nonspecific chronic low back pain, an Observational Study. J Back Musculoskelet Rehabil. 2018;31(1):147-154. doi:10.3233/BMR-169733

41. Hermens HJ, Freriks B, Merletti R, et al. SENIAM 8: European Recommendations for Surface Electromyography, Roessingh Research and Development. 1999.

42. Tylman D. Pathomechanics of Lateral Spinal Curvatures. Warsaw: Severus; 1995

43. Redford JB, Butterworth TR, Clements EL Jr. Use of electromyography as a prognostic aid in the management of idiopathic scoliosis. Arch Phys Med Rehabil. 1969;50(8):433-438.

44. Burwell RG, Dangerfield PH, Freeman BJC. Pathogenesis of adolescent idiopathic scoliosis: a collective model involving abnormality of the escalator of a normal neuro-osseous timing of maturation (NOTOM) system as the central concept. Clin Anat. 2008;21(2):195-196.

45. Joly O, Rousie D, Jissendi P, Rousie M, Franko E. A new approach to corpus callosum anomalies in idiopathic scoliosis using diffusion tensor magnetic resonance imaging. Eur Spine J. 2014;23 (12):2643-2649. doi:10.1007/s00586-014-3435-3

46. Liu T, Chu WC, Young G. MR analysis of regional brain volume in adolescent idiopathic scoliosis: neurological manifestation of a systemic disease. J Magn Reson Imaging. 2008;27(4):732-736. doi:10.1002/jmri.21321

47. Wang D, Shi L, Chu WCW, Paus T, Cheng JCY, Heng PA. A comparison of morphometric techniques for studying the shape of the corpus callosum in adolescent idiopathic scoliosis. Neuroimage. 2009;45(3):738-748. doi:10.1016/j.neuroimage.2008.12.068

48. Goldberg CJ, Moore DP, Fogarty EE, Dowling FE. Scoliosis: a review. Pediatr Surg Int. 2008;24(2):129-144. doi:10.1007/s00383007-2016-5
49. Lo YL, Teo A, Tan YE, Fook-Chong S, Guo CM, Yue WM. Motor and somatosensory abnormalities are significant etiological factors for adolescent idiopathic scoliosis. J Neurol Sci. 2015;359(1-2):117-123. doi:10.1016/j.jns.2015.10.048

50. Doménech J, Tormos JM, Barrios C, Pascual-Leone A. Motor cortical hyperexcitability in idiopathic scoliosis: could focal dystonia be a subclinical etiological factor? Eur Spine J. 2010;19(2):223-230. doi:10.1007/s00586-009-1243-y

51. Domenech J, García-Martí G, Martí-Bonmatí L, Barrios C, Tormos JM, Pascual-Leone A. Abnormal activation of the motor cortical network in idiopathic scoliosis demonstrated by functional MRI. Eur Spine J. 2011;20(7):1069-1078. doi:10.1007/s00586-0111776-8

52. Burwell RG, Dangerfield PH, Freeman BJC. Etiologic theories of idiopathic scoliosis. Somatic nervous system and the NOTOM Escalator concept as one component in the pathogenesis of adolescent idiopathic scoliosis. Stud Health Technol Inform. 2008;140:208-217.

53. Riddle HF, Roaf R. Muscle imbalance in the causation of scoliosis. Lancet. 1955;18(268):1245-1247. doi:10.1016/S0140-6736(55)91020-5

54. Bayer H. The behaviour of the dorsal extensors (erector trunci) in a case of scoliosis where the convex erector trunci had been denervated by operation. Z Orthop Ihre Grenzgeb. 1980;118(2):274-278. doi:10.1055/s-2008-1053506

55. Cassidy JD, Brandell BR, Wedge J. The role of paraspinal muscles in the pathogenesis of idiopathic scoliosis: a preliminary EMG studies. J Can Chiropr Assoc. 1987;31:179-184.

56. Farahpour N, Younesian H, Bahrpeyma F. Electromyographic activity of erector spinae and external oblique muscles during trunk lateral bending and axial rotation in patients with adolescent idiopathic scoliosis and healthy subjects. Clin Biomech. 2015;30(5):411-417. doi:10.1016/j.clinbiomech.2015.03.018

57. Stetkarova I, Zamecnik J, Bocek V, Vasko P, Brabec K, Krbec M. Electrophysiological and histological changes of paraspinal muscles in adolescent idiopathic scoliosis. Eur Spine J. 2016;25(10):31463153. doi:10.1007/s00586-016-4628-8

58. Guo LY, Wang YL, Huang YH, et al. Comparison of the electromyographic activation level and unilateral selectivity of erector spinae during different selected movements. Int $J$ Rehabil Res. 2012;35 (4):345-351. doi:10.1097/MRR.0b013e32835641c0

59. Elattar E, Saber ND, Farrag A. Predictive factors for progression of adolescent idiopathic scoliosis: a 1-Year Study. Egypt Rheumatol Rehabil. 2015;3(3):111-119. doi:10.4103/1110-161X.163943

60. Thouin JF, Mathieu PA, Aubin CÉ, Ciolofan OC. Electromyographical analysis of the back muscles on Duchenne muscular dystrophy patients. In: Sawatzky BJ, UBC Press, editors. International Research Society of Spinal Deformities, Symposium 2004; Vancouver; 2004: 293-296.

61. Trontelj JV, Fernandez JM. Single fiber EMG in juvenile idiopathic scoliosis. Muscle Nerve. 1988;11(4):297-300. doi:10.1002/ mus. 880110404

62. Tsai YT, Leong CP, Huang YC, et al. The electromyographic responses of paraspinal muscles during isokinetic exercise in adolescents with idiopathic scoliosis with a Cobb's angle less than fifty degrees. Chang Gung Med J. 2010;33(5):540-550.

63. Toosizadeh N, Chuan Yen T, Howe C, Dohm M, Mohler J, Najafi B. Gait behaviors as an objective surgical outcome in low back disorders: a systematic review. Clin Biomech. 2015;30(6):528-536. doi:10.1016/j.clinbiomech.2015.04.005

64. Minehisa K, Nara I, Endoh T. Muscle strength and electromyography of paraspinal muscles during isokinetic exercise in adolescent idiopathic scoliosis. J Phys Ther Sci. 2003;15(2):105-111. doi:10.1589/ jpts. 15.105

65. Haller G, McCall K, Jenkitkasemwong S, et al. A missense variant in SLC39A8 is associated with severe idiopathic scoliosis. Nat Commun. 2018;9(1):4171. doi:10.1038/s41467-018-06705-0 


\section{Publish your work in this journal}

Risk Management and Healthcare Policy is an international, peerreviewed, open access journal focusing on all aspects of public health, policy, and preventative measures to promote good health and improve morbidity and mortality in the population. The journal welcomes submitted papers covering original research, basic science, clinical \& epidemiological studies, reviews and evaluations, guidelines, expert opinion and commentary, case reports and extended reports. The manuscript management system is completely online and includes a very quick and fair peer-review system, which is all easy to use. Visit http://www.dovepress.com/testimonials.php to read real quotes from published authors. 